\title{
Hygroscopic growth and critical supersaturations for mixed aerosol particles of inorganic and organic compounds of atmospheric relevance
}

\author{
B. Svenningsson ${ }^{1}$, J. Rissler ${ }^{2}$, E. Swietlicki ${ }^{2}$, M. Mircea ${ }^{3}$, M. Bilde ${ }^{1}$, M. C. Facchini ${ }^{3}$, S. Decesari ${ }^{3}$, S. Fuzzi ${ }^{3}$, J. Zhou ${ }^{2}$, \\ J. Mønster ${ }^{1}$, and T. Rosenørn ${ }^{1}$ \\ ${ }^{1}$ University of Copenhagen, Department of Chemistry, Universitetsparken 5, DK-2100 Copenhagen, Denmark \\ ${ }^{2}$ Division of Nuclear Physics, Lund University, P.O. Box 118, SE-211 00 Lund, Sweden \\ ${ }^{3}$ Institute of Atmospheric Sciences and Climate (ISAC), National Research Council, Via Gobetti 101, I-40129 Bologna, Italy
}

Received: 24 January 2005 - Published in Atmos. Chem. Phys. Discuss.: 9 May 2005

Revised: 27 March 2006 - Accepted: 5 April 2006 - Published: 7 June 2006

\begin{abstract}
The organic fraction of atmospheric aerosols contains a multitude of compounds and usually only a small fraction can be identified and quantified. However, a limited number of representative organic compounds can be used to describe the water-soluble organic fraction. In this work, initiated within the EU 5FP project SMOCC, four mixtures containing various amounts of inorganic salts (ammonium sulfate, ammonium nitrate, and sodium chloride) and three model organic compounds (levoglucosan, succinic acid and fulvic acid) were studied. The interaction between water vapor and aerosol particles was studied at different relative humidities: at subsaturation using a hygroscopic tandem differential mobility analyzer (H-TDMA) and at supersaturation using a cloud condensation nuclei spectrometer ( $\mathrm{CCN}$ spectrometer). Surface tensions as a function of carbon concentrations were measured using a bubble tensiometer. Parameterizations of water activity as a function of molality, based on hygroscopic growth, are given for the pure organic compounds and for the mixtures, indicating van't Hoff factors around 1 for the organics. The Zdanovskii-Stokes-Robinson (ZSR) mixing rule was tested on the hygroscopic growth of the mixtures and it was found to adequately explain the hygroscopic growth for 3 out of 4 mixtures, when the limited solubility of succinic acid is taken into account. One mixture containing sodium chloride was studied and showed a pronounced deviation from the ZSR mixing rule. Critical supersaturations calculated using the parameterizations of water activity and the measured surface tensions were compared with those determined experimentally.
\end{abstract}

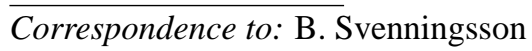

(birgitta@kiku.dk)

\section{Introduction}

In the atmosphere, the interaction between water vapor and aerosol particles has implications on several important processes (Raes et al., 2000). Among those are light scattering by aerosol particles (direct effect on climate), cloud droplet formation and growth, and, consequently cloud properties (indirect effect on climate). Uptake of water on aerosol particles also influences wet and dry deposition of aerosols and lung deposition (Schroeter et al., 2001; Ferron et al., 1988; Broday and Georgopoulos, 2001; Chan et al., 2002). In the last years there has been a special focus on the indirect effect of aerosol particles on climate (Twomey, 1977; Kaufman et al., 2002; Ramanathan et al., 2001). Recently, Penner et al. (2004) have shown observational evidence for a substantial alteration of radiative fluxes due to the indirect aerosol effect, but this effect still accounts for one of the largest uncertainties in estimates of the climate change (IPCC, 2001).

Aerosol particles are composed of a large number of organic as well as inorganic substances. The major inorganic ions are often relatively well characterized, although the picture is still incomplete concerning the distribution of these compounds over particle sizes and between individual particles within a population as well as their geographical distribution over the globe. Due to their solubility and high number of ions per volume, inorganic ions have until lately been thought to dominate the water uptake by atmospheric aerosol particles.

The organic aerosol fraction is complex (Decesari et al., 2000; Shimmo et al., 2004) and there is a lack of qualitative as well as quantitative information on the chemical composition. Therefore, modeling of the interaction between water vapor and such a multi-component mixture and,

Published by Copernicus GmbH on behalf of the European Geosciences Union. 
Table 1. Substances used in this work.

\begin{tabular}{llccclc}
\hline Substance & & Mw $(\mathrm{g} / \mathrm{mol})$ & $\left.\rho \mathrm{g} / \mathrm{cm}^{3}\right)$ & Maximum \# of ions & Supplier & Purity \\
\hline Levoglucosan & $\mathrm{C}_{6} \mathrm{H}_{10} \mathrm{O}_{5}$ & 162.0 & 1.6 & 1 & ALDRICH & $99 \%$ \\
Succinic acid & $\mathrm{C}_{4} \mathrm{H}_{6} \mathrm{O}_{4}$ & 118.0 & 1.57 & 3 & FLUKA & $>99.5 \%$ \\
Fulvic acid ${ }^{1)}$ & $\mathrm{C}_{33} \mathrm{H}_{32} \mathrm{O}_{19}$ & 732.0 & 1.5 & 5 & IHSS & - \\
Ammonium nitrate & $\mathrm{NH}_{4} \mathrm{NO}_{3}$ & 80.1 & 1.72 & 2 & MERCK SUPRAPUR & $>99 \%$ \\
Ammonium sulfate & $\left(\mathrm{NH}_{4}\right)_{2} \mathrm{SO}_{4}$ & 132.1 & 1.77 & 3 & MERCK SUPRAPUR & $>99.5 \%$ \\
Sodium chloride & $\mathrm{NaCl}$ & 58.4 & 2.17 & 2 & BDH ANALAR & $99.9 \%$ \\
\hline
\end{tabular}

1) Suwannee River Reference Fulvic Acid is in itself a mixture of many unknown substances and it is represented by an estimated average composition (Averett et al., 1989).

Table 2. Composition of the studied mixtures.

\begin{tabular}{llll}
\hline Mixtures & Composition & wt $\%$ & References \\
\hline \multirow{2}{*}{ MIXBIO } & Ammonium sulfate & $30 \%$ & Artaxo et al. (2002) \\
& Levoglucosan & $18 \%$ & Mayol-Bracero et al. (2002) \\
& Succinic acid & $27 \%$ & \\
& Fulvic acid & $25 \%$ & \\
MIXSEA & Ammonium sulfate & $50 \%$ & \\
& Sodium chloride & $30 \%$ & Raes et al. (2000) \\
& Succinic acid & $10 \%$ & \\
& Fulvic acid & $10 \%$ & \\
MIXPO & Ammonium Nitrate & $35 \%$ & Zappoli et al. (1999) \\
& Ammonium Sulfate & $35 \%$ & \\
& Levoglucosan & $6 \%$ & \\
& Succinic Acid & $12 \%$ & Decesari et al. (2001) \\
& Fulvic Acid & $12 \%$ & \\
MIXORG & Levoglucosan & $20 \%$ & \\
& Succinic acid & $40 \%$ & \\
& Fulvic acid & $40 \%$ & \\
\hline
\end{tabular}

consequently, modeling of the aerosol indirect effect on climate is an ongoing research (Kanakidou et al., 2004). Recently it has been recognized that a large fraction of the organic aerosol is water-soluble (Saxena and Hildemann, 1996; Zappoli et al., 1999). One way to handle the large number of organic compounds comprised within the water soluble atmospheric aerosol is to identify a set of model substances that can reproduce the behavior of the water-soluble organic fraction of the real aerosol particles. This approach was proposed by Fuzzi et al. (2001) and it is based on identification of model compounds by using chromatographic separation and HNMR (Proton Nuclear Magnetic Resonance) analysis. In brief, the chromatographic separation allows the partition of the complex WSOC mixture into three main classes according to the acid/base character: i) neutral compounds, ii) mono-/di-carboxylic acids, and iii) polycarboxylic acids and through the NMR analysis and TOC (Total Organic Carbon) measurements a model compound can be associated to each class.
Based on this work, it is of interest to study the interaction of water with mixed particles containing levoglucosan, succinic acid, and fulvic acid (Table 1 and 2) as examples of neutral compounds, mono/di-carboxylic acids, and polyacids, respectively. Levoglucosan is a tracer for biomass burning (Simoneit et al., 1999) and succinic acid is one of many dicarboxylic acids often identified in atmospheric aerosol samples (Chebbi and Carlier, 1996; Kerminen et al., 2000; Kawamura et al., 2001a and b; Narukawa et al., 2002).

Also, it has been shown (Charlson et al., 2001; Nenes et al., 2002) that some of the water-soluble organic compounds (WSOC) are surface-active and can have significant effects on water uptake and cloud droplet activation of aerosol particles not only by contributing to the soluble mass but also by reducing the surface tension (Facchini et al., 1999).

During the last years several studies on water uptake of organic compounds (Kanakidou et al., 2005 and references therein) as well as of their ability to form cloud drops (e.g. Raymond and Pandis, 2002 and 2003; Henning et al.,2005; Kanakidou et al., 2005 and references therein) have been reported in the literature. Among the organic substances analyzed in this study, succinic acid (Cruz and Pandis, 1997; Corrigan and Novakov, 1999; Prenni et al., 2001; Peng et al., 2001; Hori et al., 2003; Bilde and Svenningsson, 2004; Broekhuizen et al.,2004) and Suwannee River fulvic acid (Chan and Chan, 2003; Brooks et al., 2004) have been studied previously at subsaturation, supersaturation, or both. Still, thermodynamic data needed for modeling cloud droplet activation are not available for most WSOC of atmospheric relevance. There is especially an urgent need of more data on mixtures similar to those found in the atmosphere.

In the present work, which forms part of the EU project SMOCC (Smoke Aerosols, Clouds, Rainfall, and Climate: Aerosols from Biomass Burning Perturb Global and Regional Climate, Andreae et al., 2004) we have studied the behaviour of mixed aerosol particles made of inorganic and organic compounds. The chemical composition of the mixtures was based on analysis of ambient aerosols at different geographical locations (Table 2). The organic aerosol was represented by model compounds derived as in the work by 


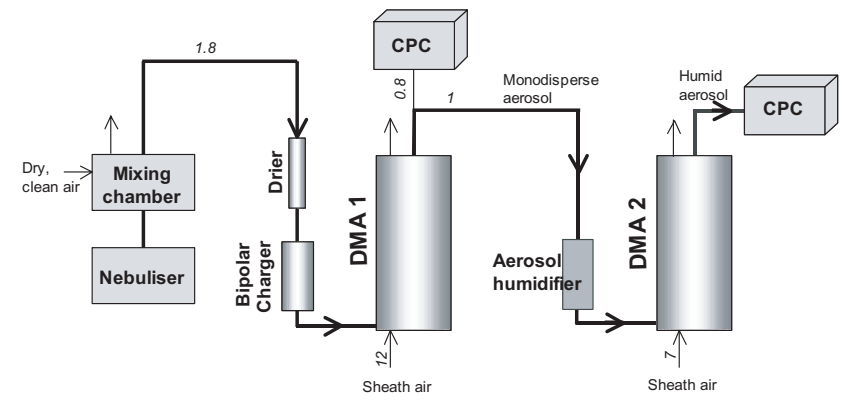

Fig. 1a. Hygroscopic growth experimental set up. In DMA 1 particles in a narrow size range are selected from the dry aerosol. The aerosol flow is then humidified and the new size of the particles is determined using DMA 2 (with $R H$ controlled sheath air) and a particle counter. The temperature is measured at 5 different positions before and after DMA 2.

Fuzzi et al. (2001). The interaction between aerosol particles and water vapor was studied at water vapor subsaturation, using the Hygroscopic Tandem Differential Mobility Analyzer (H-TDMA) at the University of Lund, and at supersaturation, using the Cloud Condensation Nucleus spectrometer (CCN spectrometer) at the University of Copenhagen. As an important input in converting relative humidity to water activity and in relating subsaturation and supersaturation data, the surface tension as a function of concentration of organic material was measured, at CNR in Bologna.

To predict water uptake of pure and mixed aerosols the socalled Zdanovskii-Stokes-Robinson (ZSR) method (Stokes and Robinson, 1966) has been the method of choice in several recent studies (Kanakidou et al., 2005 and references therein). The ZSR method relies on the assumption that the individual compounds in a solution do not interact. Other approached have also been used to predict water uptake (e.g. Ansari and Pandis, 2000). Since the ZSR method is relatively simple and very often used we choose to test the ZSR method on the mixtures studied herein.

This work aims at the following: 1) producing new parameterisations for the water activity as a function of concentration for a series of organic model compounds and inorganic/organic mixtures of atmospheric interest, based on hygroscopic growth as a function of relative humidity, 2) testing the applicability of the Zdanovskii-Stokes-Robinson (ZSR) method (Stokes and Robinson, 1966) to the studied mixtures, and 3) predicting critical supersaturations based on the obtained parameterizations of water activity as a function of concentration and comparing them with those found experimentally.

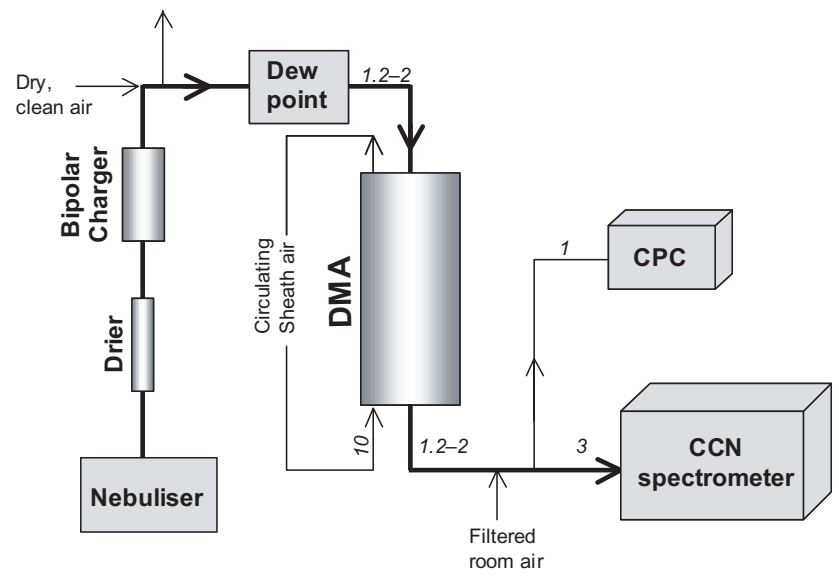

Fig. 1b. CCN spectrometer experimental set up. Particles in a narrow size range are selected from the dry aerosol. The monodisperse aerosol flow is split between the $\mathrm{CCN}$ spectrometer, detecting the number of activated droplets as a function of supersaturation, and a particle counter (CPC), giving the total number of particles. Since the CCN spectrometer and the particle counter together need an aerosol flow of about $4 \mathrm{l} / \mathrm{min}$ and we want to keep the aerosol flow in the DMA low to get a good resolution, the aerosol flow is diluted between the DMA and the flow split.

\section{Experimental}

\subsection{Chemicals and sample preparation}

Based on chemical analyses of aerosol sampled in various types of air masses, a set of organic and inorganic compounds were chosen to represent the composition of the aerosol particulate matter (Table 1). The selected inorganic compounds were: ammonium sulfate, sodium chloride and ammonium nitrate. Following the approach proposed by Fuzzi et al. (2001), the organic aerosol fraction was represented by: levoglucosan, succinic acid and fulvic acid. Fulvic acid is not a single well-defined chemical compound and the data reported in the table refer to average formulas, chemical structure and physical properties, estimated for the employed reference material (Averett et al., 1989). Using these compounds and the data on chemical composition of different aerosol types, three mixtures representative for atmospheric aerosols of various types were prepared. The mixtures were prepared on mass weight basis and the mass percentage of each compound is presented in Table 2. The MIXBIO mixture represents the aerosol in biomass burning regions and is based on data from Artaxo et al. (2002) and Mayol-Bracero et al. (2002). MIXSEA represent the marine aerosol and is based on the work of Raes et al. (2000). MIXPO is based on work by Decesari et al. (2001) and Zappoli et al. (1999) and represents continental, polluted aerosol. MIXORG is a mixture of the 3 organic compounds included in the three mixtures above, i.e. levoglucosan, succinic acid, and fulvic acid. 
The aerosol was produced from the aqueous solution of the single compound or the mixture in a small nebulizer (Microneb, Lifecare Hospital Ltd, UK), originally designed for medical purposes. The advantage of using this nebulizer is that it only requires $5-10 \mathrm{ml}$ of sample volume. A low flow rate $(3 \mathrm{l} / \mathrm{min})$ was used in the nebulizer, to make the sample last as long as possible $(2-3 \mathrm{~h})$. The H-TDMA and $\mathrm{CCN}$ spectrometer measurements where performed in two different laboratories and slightly different drying procedures where used.

\subsection{Hygroscopic growth measurements}

The measurements at subsaturations were performed with a Hygroscopic Tandem DMA (Differential mobility analyzer). This instrument mainly consists of three parts: (1) A Differential Mobility Analyzer (DMA1) that selects particles in a narrow, quasi-monodisperse size range of dry particles $(R H<10 \%)$ from a polydisperse aerosol, (2) humidifiers bringing the aerosol to a controlled humidified state, and (3) a second DMA (DMA2) that together with a particle counter (TSI) measures the change in size caused by the imposed humidification (Fig. 1a). The aerosol and the sheath flow entering DMA2 are humidified separately.

This H-TDMA can be operated in two different modes: scanning $R H$ for particles of one dry size, or scanning dry size at a fixed $R H$. During these measurements mainly the $R H$ scanning mode was used, scanning $R H$ from 20 to $98 \%$, measuring the growth of $100 \mathrm{~nm}$ particles, but also the sizescanning mode was used, scanning dry sizes between 30 $200 \mathrm{~nm}$. More detailed descriptions of the H-TDMA system as well as tests of its ability to reproduce literature data on water activity as a function of concentration are given by Svenningsson et al. (1997) and Zhou (2001). In this work, the H-TDMA performance was verified using ammonium sulfate and sodium chloride.

\subsubsection{Quality assurance}

When running the H-TMDA program, a large number of status parameters such as temperatures, dew point temperature, pressures and flows are logged. The raw data obtained by the H-TDMA were evaluated and quality-assured off-line.

The amount of water vapor in DMA2 was determined with a dew point hygrometer. In order to determine $R H$ in the $\mathrm{H}$ TDMA, the temperature in the second DMA has to be determined. To do this with as high accuracy as possible, the hygroscopic growth of a standard aerosol of pure ammonium sulfate was measured and compared to the modeled growth using the parameterizations given by Tang and Munkelwitz (1994). Salt scans were performed regularly, and for $R H$ above $95 \%$ the H-TDMA was scanning alternately between ammonium sulfate and the compound investigated, for each $R H$-setting. The temperature in DMA2 was then determined from the salt scans and expressed as a linear combination of the temperatures measured at various positions before and after the second DMA. Since $R H$ increases exponentially with dew point temperature (resulting in larger variation in $R H$ due to variations in temperature, for higher $R H$ ), the temperature for scans at $R H$ above $95 \%$ was more precisely determined directly from the salt scan. During all these measurements the temperature of the H-TDMA was in the range $21-24^{\circ} \mathrm{C}$.

To parameterize the hygroscopic growth factor distribution of the aerosol, the spectra were fitted with a fitting program developed in Lund (Zhou, 2001), based on the theory and algorithm of "TDMAFIT" developed by Stolzenberg and McMurry (1988). This inversion estimates the arithmetic mean diameter growth factor, (defined as the ratio between the dry and conditioned particle diameter) the diameter growth dispersion factor and the number fractions of particles in the hygroscopic particle group.

\subsection{CCN spectrometer measurements}

The critical supersaturation as a function of dry particle size was measured using a thermal gradient diffusion Cloud Condensation Nucleus spectrometer (CCN spectrometer, University of Wyoming, CCNC-100B). The supersaturation in the detection volume depends on the temperatures of the top and bottom plates, under the assumption that the air is saturated with water near the plates. The supersaturation was calibrated using the activation of sodium chloride and ammonium sulfate particles of various dry sizes. The droplet number concentration is based on the intensity of light scattered by droplets within the sensitive volume, and was calibrated at the University of Wyoming. The instrument was used in a scanning mode, i.e. the number of detected activated droplets for a given dry particle size was measured for up to $20 \mathrm{su}-$ persaturations in the range $0.2-2 \%$. Critical supersaturations were obtained by finding the supersaturation for which $50 \%$ of the particles of a given diameter were activated and the given values are averages from 3-5 scans. All measurements of critical supersaturations presented here were made with temperatures in the center of the CCNC chamber between 25 and $29^{\circ} \mathrm{C}$. The calculations of critical supersaturations were made for $25^{\circ} \mathrm{C}$, resulting in errors of less than $2 \%$ of the obtained critical supersaturations.

The aerosol was dried to a relative humidity between 5 and $15 \%$ in diffusion driers and given a charge distribution by letting it pass a $\mathrm{Kr}^{85} \beta$-source. A narrow size fraction was selected using a Differential Mobility Analyzer (DMA, TSI 3080). A DMA selects particles according to their electrical mobility, which means that the selected particles with multiple charges have larger diameters than the majority carrying a single charge. The fraction of particles that are doubly charged is normally low, and their activation was observed in the CCNC data and taken into account in the data evaluation. The width of the size distribution exiting a DMA is determined by the ratio between the aerosol flow and the sheath 
Table 3. Parameterization of surface tension as a function of concentration. The surface tension of the inorganic compounds increases with concentration according to $\sigma_{S}=\sigma_{0}+\beta c$, where $\sigma_{0}$ is the surface tension of pure water and $\mathrm{c}$ is the molality of the inorganic compound. For the organic compounds and the mixtures, the surface tension is described as a function of the concentration of water-soluble carbon $\sigma_{s}=\sigma_{0}-\alpha T \ln (1+\beta c)$, where $c$ is the number of moles of carbon atoms per kilogram of water and $T$ is the temperature.

\begin{tabular}{|c|c|c|c|}
\hline Substance & $\beta\left(\mathrm{kg} \mathrm{mole}^{-1} \mathrm{mN} \mathrm{m}^{-1}\right)$ & & \\
\hline Ammonium Nitrate & 0.384 & & \\
\hline Ammonium Sulfate & 2.362 & & \\
\hline \multirow[t]{2}{*}{ Sodium Chloride } & 1.62 & & \\
\hline & $\alpha\left(\mathrm{mN} \mathrm{m}^{-1} \mathrm{~K}^{-1}\right)$ & $\beta\left(\mathrm{kg} \mathrm{mole}^{-1}\right)$ & $\begin{array}{l}\text { Min measured surface } \\
\text { tension }\left(\mathrm{mN} \mathrm{m}^{-1}\right)\end{array}$ \\
\hline Levoglucosan & 0.0028 & 0.813 & 70 \\
\hline Succinic acid & 0.0264 & 0.286 & 67 \\
\hline Fulvic acid & 0.0286 & 23.088 & 52 \\
\hline MIXSEA & 0.0437 & 5.0429 & 44 \\
\hline MIXBIO & 0.0175 & 50.000 & 48 \\
\hline MIXPO & 0.0316 & 7.692 & 48 \\
\hline MIXORG & 0.0206 & 16.004 & 48 \\
\hline
\end{tabular}

flow in the DMA. Sheath flows of $101 / \mathrm{min}$ and aerosol flows of $1.2-21 / \mathrm{min}$ were used.

The quasi-monodisperse aerosol was diluted with filtered room air and split into two flows (Fig. 1b). One was directed to the CCN spectrometer and the other to a particle counter (CPC, TSI 3010) to be used as a number reference. The reason for the dilution is that the $\mathrm{CCN}$-spectrometer needs $31 /$ min and the CPC $11 /$ min while the aerosol to sheath air flow-ratio in the DMA should be kept low. The $31 / \mathrm{min}$ flow through the CCN spectrometer is only needed while flushing the chamber, but a bypass flow was used the rest of the time to avoid changes in the flow through the DMA.

The error estimates for the critical supersaturation are $95 \%$ confidence intervals based on the calibration data for the $\mathrm{CCN}$ spectrometer. Sodium chloride and ammonium sulfate were used for the calibration. A van't Hoff factor of 2 was used for sodium chloride while for ammonium sulfate, it was adopted from the literature (Low, 1969; Young and Warren, 1992) and ranges between 2.2-2.4 at the point of activation. H-TDMA data on sodium chloride supports the use of a shape factor for a cube, i.e. 1.08, but the shape factor in the $\mathrm{CCN}$ spectrometer analysis can be slightly different since the particles were not dried in exactly the same way. A unity shape factor for sodium chloride was applied for the CCN spectrometer calibration, but the possibility of the particles being cubic-shaped was included in the error estimate.

\subsection{Surface tension measurements}

The surface tension as a function of concentration was determined using a SINTECH (Berlin, Germany) PAT1 tensiometer. The instrument determines the surface tension of a liquid from the shape of a pendant drop or bubble. The shape of a bubble or drop is given by the Gauss-Laplace equation, which represents a relationship between the curvature of a liquid meniscus and the surface tension (Loglio et al., 1998). Only recently, this method became available as commercial instrument allowing surface tension measurements with an accuracy of $\pm 0.1 \mathrm{mN} / \mathrm{m}$. The variation of surface tension as a function of WSOC concentration is described by the Szyszkowski-Langmuir equation (Langmuir, 1917)

$\sigma_{s}=\sigma_{0}-\alpha T \ln (1+\beta c)$

where $T$ is the temperature $(\mathrm{K})$ and $c$ is the concentration of soluble carbon in moles of carbon $\mathrm{kg}^{-1}$ of water. The two constants $\alpha$ and $\beta$ were determined for each sample by fitting the measurements of surface tension and the corresponding WSOC concentration at fixed temperature with the Szyszkowski-Langmuir equation. $\sigma_{0}$ represent the surface tension of pure water at the temperature of measurements.

Previous work (Facchini et al., 1999; Decesari et al., 2003) have shown that this equation well describes the surface tension changes in atmospheric water, and it was shown that the surface coverage of WSOC surfactants is mainly controlled by the bulk concentration of WSOC. In the case of micrometer sized droplets and strongly surface active compounds, Eq. (1) tends to underestimate the surface tension because the bulk concentration becomes depleted due to the partitioning of the surfactant into the surface phase (Li et al., 1998). However, the partitioning effects demonstrated for sodium dodecyl sulfate (SDS) might be less important in the case of atmospheric surfactants (Rood and Williams, 2001; Sorjamaa et al., 2004; Facchini et al., 2001). Therefore, in this work we used the surface tension data as suggested by Decesari et al. (2003), i.e. as being independent of the available surface area. 
To describe the surface tension changes of pure inorganic solutions we have used the empirical relation suggested by Hänel (1976):

$\sigma_{S}=\sigma_{0}+\beta c$

where $c$ is the concentration of inorganic salt in moles $\mathrm{kg}^{-1}$ of water.

The results from the surface tension measurements of the organics and the mixtures are presented in Figs. 2a and b. The values of the parameters used in Eqs. (1) and (2) are presented in Table 3.

\subsection{Data evaluation}

The equilibrium water vapor pressure ( $p$ ) over a droplet surface containing a single solute in water can be expressed using the Köhler equation, i.e. the combination of Raoult's law for water activity $a_{w}$ and the Kelvin curvature effect as:

$R H=\frac{p}{p_{0}}=a_{w} \exp \left(\frac{4 \sigma M_{\text {water }}}{\rho_{\text {water }} R T d}\right)$

where $p_{0}$ is the equilibrium water vapor pressure above a flat surface of pure water, $\sigma$ is the surface tension, $M_{\text {water }}$ the molar weight of water, $\rho_{\text {water }}$ the density of water, $R$ the universal gas constant, $T$ the temperature, and $d$ the droplet diameter.

$a_{w}=\frac{n_{\text {water }}}{n_{\text {water }}+i n_{s}}=\frac{1}{1+i M_{\text {water }} m_{s}}$

where $n_{\text {water }}$ and $n_{s}$ are the number of moles of water and solute, respectively, $m_{s}$ the molality of the solute. Non-ideality can be taken care of by the van't Hoff factor $(i)$, which is allowed to vary with solution concentration.

Using the Maclaurin formula (see for example Zill and Cullen, 2000), a serial approximation of Raoult's law as a function of molality for a constant van't Hoff factor is obtained (Eq. 5), with factors only depending on the molar weight of water and the van't Hoff factor.

$$
\begin{gathered}
a_{w}\left(m_{s}\right) \approx 1-i M_{w} m_{s}+\left(i M_{w}\right)^{2} m_{s}^{2}-\left(i M_{w}\right)^{3} m_{s}^{3} \\
+\left(i M_{w}\right)^{4} m_{s}^{4}-\left(i M_{w}\right)^{5} m_{s}^{5}+\ldots .
\end{gathered}
$$

In cloud physics, an approximation considering only the linear term is often used. Used with a fix $i$, this simplification is only valid for diluted drops and could not be used in interpreting hygroscopic growth data. To investigate if hygroscopic growth follows Raoult's law with a constant van't Hoff factor, Eq. (5) will be compared with the polynomial fits obtained from the experimental data.

Some other parameterizations of water activity based on hygroscopic growth have been used in order to calculate critical supersaturations (Svenningsson et al., 1994; Brechtel and Kreidenweis, 2000; Kreidenweis et al., 2005). These can be especially useful when data for only a few relative humidities are available, as e.g. for data on ambient aerosols.
Data on hygroscopic growth as a function of relative humidity were used to get a polynomial parameterization of the water activity as a function of molality (Table 4). To be able to do this, water activity was calculated from the relative humidity and molality from the hygroscopic growth. In going from $R H$ to water activity for a submicrometer droplet, the $R H$ is divided by the Kelvin curvature term (Eq. 3). The measured surface tensions were used in the concentration range covered by the measurements. For higher concentration, the lowest measured surface tension is used (Table 3).

For the pure compounds, the molality of compound s $\left(m_{s}\right)$ in the droplet is calculated as

$$
\begin{aligned}
m_{s} & =\frac{n_{s}}{\operatorname{mass}_{\text {water }}}=\frac{\rho_{s} \frac{\pi}{6} d_{0}^{3} / M_{s}}{\rho_{\text {water } \frac{\pi}{6}}\left(d_{R H}^{3}-d_{0}^{3}\right)} \\
& =\frac{\rho_{s}}{M_{s} \rho_{\text {water }}\left(D G F_{R H}^{3}-1\right)}
\end{aligned}
$$

where $\rho_{s}$ and $\rho_{\text {water }}$ are the densities of compound s and water, respectively, $d_{0}$ is the dry particle diameter, $d_{R H}$ is the diameter at the higher relative humidity, and $M_{S}$ is the molar weight of the dry solute. The $D G F_{R H}$ represents the diameter growth factor measured by the H-TDMA and is defined as the ratio between the particle diameter at the given relative humidity and the dry particle diameter. As could be seen from Eq. (6), $m_{s}$ depends on the density and the molar weight of the material. For concentrated solutions and for substances with low solubility, the solubility can also put a limit on $m_{s}$.

To obtain molalities for the mixtures from hygroscopic growth data, the total number of molecules in a mixture, $n_{\text {tot }}$, replaces $n_{s}$ in Eq. (6) and is given as:

$n_{\text {tot }}=\rho \frac{\pi}{6} d_{0}^{3} \sum_{s} \frac{\varepsilon_{m, s}}{M_{s}}$

In general, the densities of the dry, mixed particles are not known. To estimate densities of the dry, mixed particles we therefore assume that both masses and volumes are additive when two or more compounds are mixed.

$\frac{1}{\rho}=\sum_{s} \frac{\varepsilon_{m, s}}{\rho_{s}}$

where $\varepsilon_{m, s}$ is the mass fraction of compound $s$ in the dry particle. The same assumption is used in the molality calculation above (Eq. 6) to get the amount of water.

The ZSR method to estimate the water activity of a mixture, using the water activities of the pure compounds, is defined by the following equation:

$1=\sum_{s} \frac{m_{s}\left(a_{w}\right)}{m_{o, s}\left(a_{w}\right)}$

where $m_{s}$ is the molality of compound $s$ in the mixture and $m_{o, s}$ is the molality of the single electrolyte solution of component $s$ for which the water activity equals that of the 
Table 4. Parameters in the polynomial fit of the H-TDMA data. $a_{w}\left(m_{s}\right)=1+a_{1} m_{s}+a_{2} m_{s}^{2}+a_{3} m_{s}^{3}+a_{4} m_{s}^{4}+a_{5} m_{s}^{5}$. The parameterization is valid for molalities lower than $m_{\max }$ indicated in the table. The errors in the molality, caused by the uncertainty in the growth factor measurements, have also been parameterized. Due to the nonlinearity in the conversion from growth factor to molality, the errors are not symmetrical. The errors in the direction of increasing molality $(m)$ are described as $d m / m=a_{+} m+b_{+}$and those in the direction of decreasing molality as $-d m / m=a_{-} m+b_{-}$. It should be pointed out that all factors in the parameterizations has to be used, especially for concentrated solutions. For comparison, the serial approximation of Raoult's law for a constant van't Hoff factor of 1 is given.

\begin{tabular}{|c|c|c|c|c|c|c|c|c|c|c|c|}
\hline Substance/Mixture & $a_{1}$ & $a_{2}$ & $a_{3}$ & $a_{4}$ & $a_{5}$ & $R^{2}$ & $m_{\max }$ & $a_{+}$ & $b_{+}$ & $a_{-}$ & $b_{-}$ \\
\hline Levoglucosan & -0.0159 & $2.77 * 10^{-4}$ & $-3.36^{*} 10^{-6}$ & $1.72 * 10^{-8}$ & - & & 50 & 0.0095 & 0.0142 & 0.0047 & 0.0386 \\
\hline Succinic Acid & - & - & - & - & - & & & & & & \\
\hline Fulvic Acid & -0.0101 & $-3.11 * 10^{-4}$ & $1.62 * 10^{-5}$ & $-1.95 * 10^{-7}$ & - & & 20 & 0.0757 & 0.1895 & 0.0169 & 0.0771 \\
\hline Ammonium Nitrate & - & - & - & - & - & & & & & & \\
\hline MIXBIO & -0.0148 & $-4.71 * 10^{-3}$ & $1.23 * 10^{-3}$ & $-1.23 * 10^{-4}$ & $4.32 * 10^{-6}$ & & 11 & 0.0092 & 0.0188 & 0.0074 & 0.0205 \\
\hline MIXSEA & -0.0151 & $-1.70^{*} 10^{-3}$ & $2.08 * 10^{-4}$ & $-9.62 * 10^{-6}$ & $1.54 * 10^{-7}$ & & 17 & 0.0054 & 0.0237 & 0.0044 & 0.0244 \\
\hline MIXORG & $-7.80^{*} 10^{-3}$ & $9.93 * 10^{-5}$ & $-9.69 * 10^{-7}$ & $4.58 * 10^{-9}$ & - & & 140 & 0.0083 & 0.0031 & 0.0031 & 0.0436 \\
\hline MIXPO & $-1.91 * 10^{-2}$ & $-7.19 * 10^{-5}$ & $4.08 * 10^{-5}$ & $-1.95^{*} 10^{-6}$ & $2.94 * 10^{-8}$ & & 30 & 0.0056 & 0.0242 & 0.0041 & 0.0271 \\
\hline Van't Hoff factor $=1$ & -0.018 & $3.24 * 10^{-4}$ & $-5.83 * 10^{-6}$ & $1.05 * 10^{-7}$ & $-1.89 * 10^{-9}$ & & & & & & \\
\hline
\end{tabular}

solution mixture. In this work we use the ZSR method expressed as

mass $_{\text {water_tot }}=\sum_{s}$ mass $_{\text {water_s }}$

where mass $_{\text {water_tot }}$ is the mass of water in the mixture at the given water activity and mass water $\__{S}$ is the mass of water that would have been associated with the amount of the single electrolyte present in the mixed particle at the given water activity.

The parameterizations of water activity as a function of molality obtained from H-TDMA data were used to calculated critical supersaturations (maximum value of Eq. 3), in order to compare with experiments. The ZSR method applied to Raoult's law gives another, simple model for the water activity of a mixture $\left(a_{w}\right)$,

$a_{w}=\frac{1}{1+M_{\text {water }} \sum_{s}\left(i_{s} m_{s}\right)}$

if the van't Hoff factors for the pure compounds $\left(i_{s}\right)$ are known. Also this expression for the water activity was tested against experiments

\section{Results and discussion}

\subsection{Pure compounds}

3.1.1 Sodium chloride, ammonium sulfate, and ammonium nitrate

The hygroscopic growth of the same batch of ammonium sulfate as used in the mixtures was compared to the ammonium sulfate salt used for temperature calibration. Their hygroscopic behaviours were identical within experimental errors and agreed well with literature data for $R H<95 \%$. At
$R H>95 \%$, ammonium sulfate is used in the H-TDMA as a reference in order to calibrate the temperature in the second DMA.

Also the hygroscopic behaviour of sodium chloride was studied. The hygroscopic growth found in this study is somewhat lower than calculated from electrodynamic balance data of water activity as a function of mass fraction of solute (Tang, 1996). This is expected since many studies have shown that the $\mathrm{NaCl}$-particles are of cubic or even more agglomerated shape, the shape being dependent on the drying process (Gysel et al., 2002; Pöschl et al., 2000). In our case a dynamic shape factor (see e.g. Hinds, 1999) of 1.08-1.09 has to be applied to reproduce the result of Tang (corresponding to a cubic shape or a change in selected dry volume equivalent diameter from 100 to $\sim 95 \mathrm{~nm}$ ).

The measured hygroscopic growth of ammonium nitrate (Fig. 3a) at subsaturations was substantially lower than that calculated from activity data of Tang et al. (1996) or the AIM-model (Clegg et al., 1998; Wexler and Clegg, 2002; http://www.hpc1.uea.ac.uk/ e770/aim.html). In order to reproduce the growth calculated from the data given by Tang, the selected dry diameter $(100 \mathrm{~nm})$ had to be corrected down to $87 \mathrm{~nm}$. No deliquescence point was detected, indicating that the particles still could be in some liquid-like state also at the low $R H$ in the first DMA. Ammonium nitrate has previously been studied at several occasions using the same equipment in Lund. All these results are in agreement with the present study. Mikhailov et al. (2003) have also analyzed the hygroscopic behavior of ammonium nitrate using an $\mathrm{H}$ TDMA. They as well did not see any deliquescence behavior of the aerosol particles and they measure a lower particle hygroscopic growth than predicted from Tang's water activity data. In order to reproduce Tang's water activity data they need a change in dry particle diameter from 99 (selected dry mobility diameter) down to $89 \mathrm{~nm}$. They explain the lower growth with chemical decomposition and evaporation, 


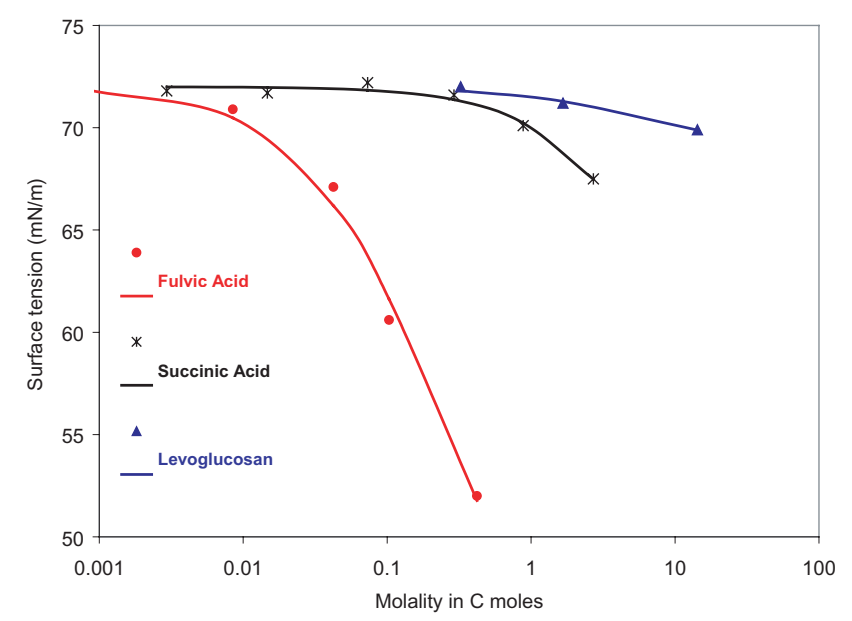

Fig. 2a. Measured surface tension as a function of concentration for the pure organic compounds. The lines represent the fitted curves (table 3): $\sigma_{s}=\sigma_{0}-\alpha T \ln (1+\beta c)$.

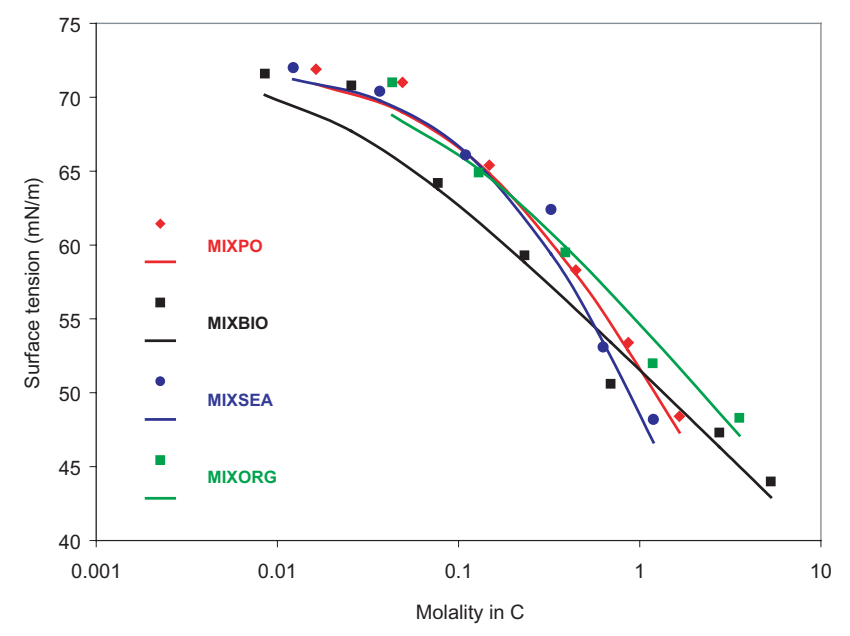

Fig. 2b. Measured surface tension as a function of concentration for the mixtures. The lines represent the fitted curves (Table 3): $\sigma_{s}=\sigma_{0}-\alpha T \ln (1+\beta c)$.

or the particle preconditioning leading to differences in particle density. The water activity as a function of molality for ammonium nitrate is presented in Fig. 4a. The calculations are made assuming that the particles were dry in DMA1 and had a density according to Table 1 . Since these assumptions may not be realistic, no parameterization is given in Table 4 .

In the $\mathrm{CCN}$ spectrometer analysis, sodium chloride and ammonium sulfate are used in the calibration of the supersaturation. Therefore, no data on these two compounds are presented here.

The critical supersaturations for ammonium nitrate particles of various diameters, agrees well with those expected from Köhler theory with a van't Hoff factor of 2. Calculations based on the parameterization of water activity as a function of molality from the H-TDMA data for ammonium nitrate overestimates the critical supersaturation (Fig. 5a).

\subsubsection{Levoglucosan}

The hygroscopic growth of levoglucosan is presented in Fig. 3a. The solid line represents calculated growth based on parameterization of water activity (Table 4 ). No deliquescence point is observed. This could be due to a high solubility and consequently a small growth factor at $R H$ just above the deliquescence point or that the particles were not completely dry in the first DMA. These results are in agreement with other resent studies (Mochida and Kawamura, 2004; Chan et al., 2005). The size dependence of the growth factors was investigated and found to agree well with that expected from the variation of the Kelvin effect with droplet diameter. In the calculation of the Kelvin effect, the parameterization of the surface tension given in Table 3 was applied. Levoglucosan has a very small effect on the surface tension (Fig. 2a).

The parameterization of water activity as a function of molality (Fig. 4a and Table 4) agrees well with that expected for a van't Hoff factor of 1 or just below, see Fig. 4a. Using this parameterization together with surface tension data reveals predicted critical supersaturations that are slightly above those found experimentally, but within the error bars (Fig. 5a).

\subsubsection{Succinic acid}

For succinic acid, no hygroscopic growth was observed at relative humidities below $98.5 \%$ (Fig. 3a). This is in agreement with the results of e.g. Peng et al. (2001) who used an electrodynamic balance to study the water cycle of some organic acids. They exposed originally dry succinic acid particles to relative humidities of up to $90 \%$ and observed no water uptake. These observations of very high deliquescence points for succinic acid are in agreement with its limited solubility. Starting with a liquid droplet, Peng et al. (2001) showed that succinic acid particles exist in supersaturated solutions down to $60 \%$ relative humidity. The effect of this limited solubility on the hygroscopic behavior of the mixed particles is discussed in the sections about MIXORG and MIXBIO.

The limited solubility of succinic acid affected the CCN spectrometer measurements as well. For particles smaller than about $80 \mathrm{~nm}$ in diameter, no well-defined critical supersaturation was observed. In a separate study on the $\mathrm{CCN}$ activation of succinic acid it was found that, due to its limited solubility, the effect of trace amounts of soluble impurities on the critical supersaturation is large. Taking this effect into account, the observed critical supersaturations agreed well with a van't Hoff factor of 1 for succinic acid (Bilde and Svenningsson, 2004).

A van't Hoff factor close to 1 is in agreement with electrodynamic balance data (Peng et al., 2001) and is expected 


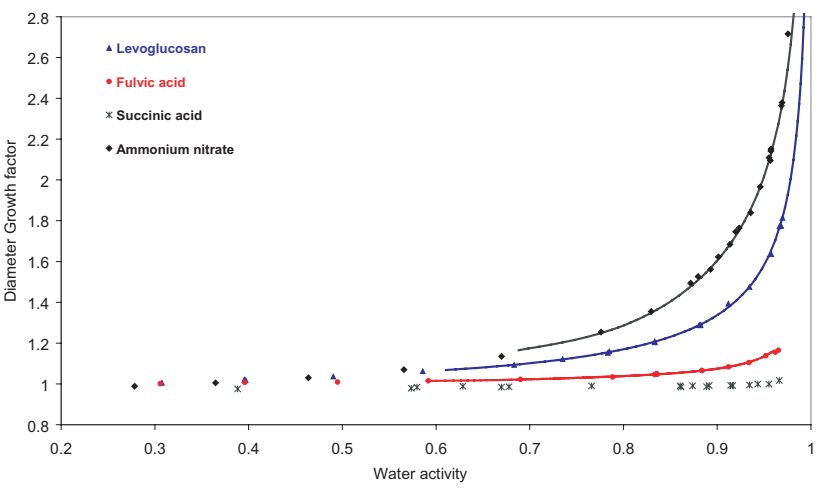

Fig. 3a. Hygroscopic diameter growth as a function of water activity for the pure substances. The solid lines are calculated hygroscopic growth from the parameterizations of water activity as a function of molality (Table 4).

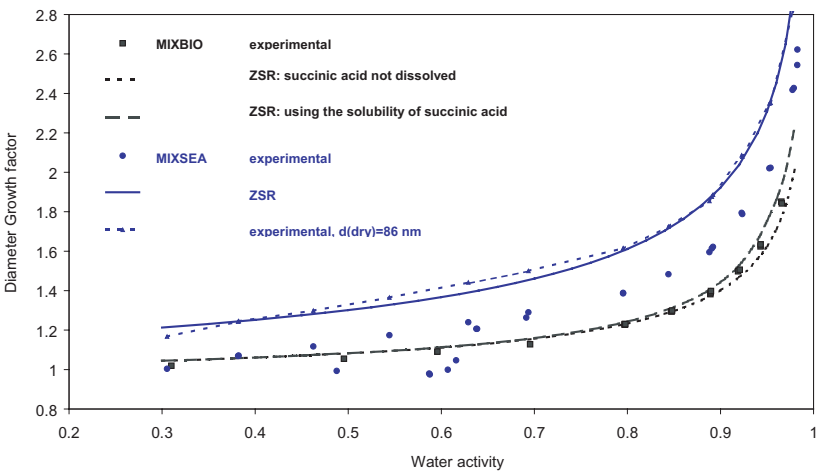

Fig. 3b. Hygroscopic diameter growth for the mixtures MIXSEA and MIXBIO. The estimated hygroscopic growth using the ZSR method is also given (solid lines). In the case of MIXBIO, the effect of taking succinic acid into account according to its solubility is demonstrated. For MIXSEA, the small blue triangles represent the experimental results, assuming that the effective dry diameter was $86 \mathrm{~nm}$ instead of $100 \mathrm{~nm}$, e.g. due to a shape factor of 1.2.

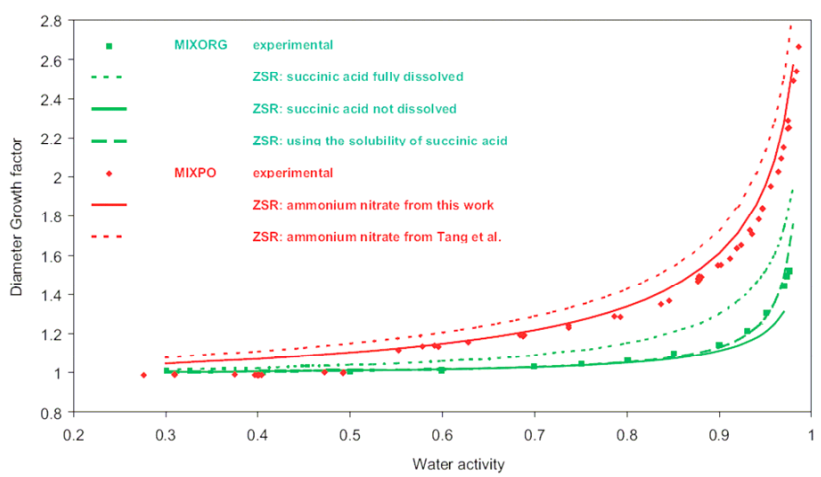

Fig. 3c. Same as Fig. 3b, but for MIXPO and MIXORG. Since the hygroscopic behavior of ammonium nitrate in this work differ from that given by Tang et al. (1996), the hygroscopic growth for MIXPO according to ZSR, was calculated using our measured growth of ammonium nitrate particles (solid red line) and the growth based on Tangs data (dotted red line).
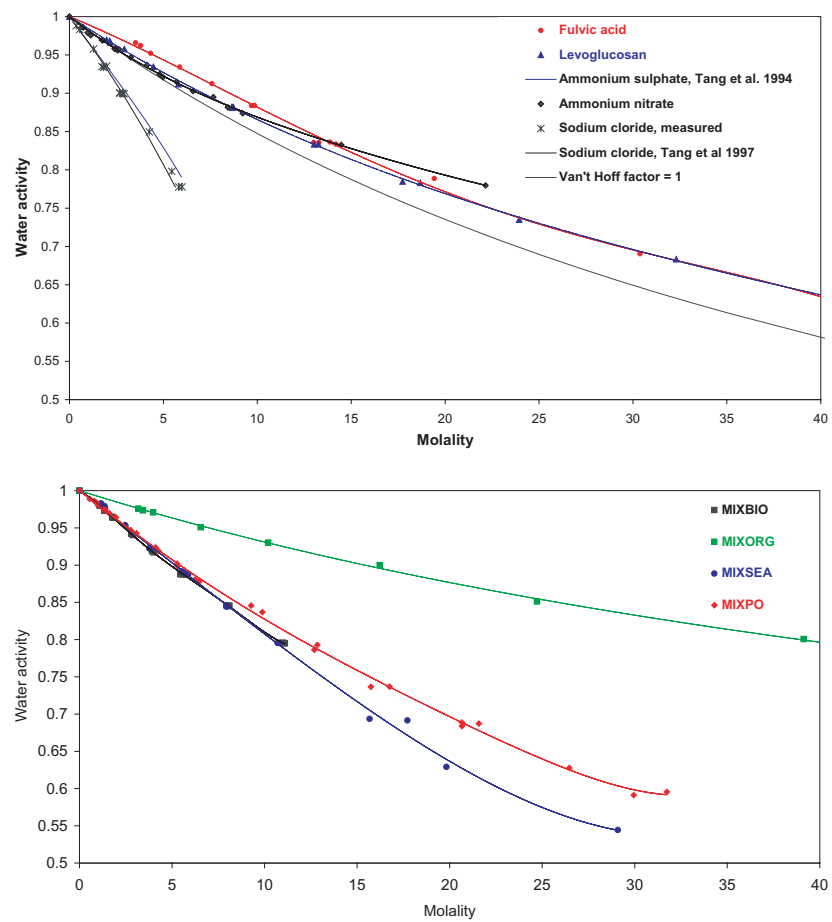

Fig. 4. Water activity as a function of molality based on hygroscopic growth data: (a) the pure compounds and (b) the mixtures. The lines represent the polynomial fits (Table 4). Ammonium sulfate and sodium chloride from the work by Tang et al. (1994 and 1996) as well as a curve representing a van't Hoff factor of 1 (Eq. 6) are included for comparison. No data for succinic acid are given, since no growth was observed.

due to the low dissociation constant for succinic acid. Thus, in using the ZSR method to estimate the hygroscopic growth of mixed particles, succinic acid is included with a constant solubility of $88 \mathrm{~g} / \mathrm{l}$ water (Saxena and Hildemann, 1996) and a van't Hoff factor of 1 . Succinic acid introduces some reduction in the surface tension (Fig. 2a).

\subsubsection{Fulvic acid}

Fulvic acid cannot be described as a pure compound, but rather as a mixture of compounds with different mole weights, densities, van't Hoff factors, and influence on the surface tension (Averett et al., 1989). It is also by far the most surface-active compound in this study (Fig. 2a).

The parameterization of water activity as a function of molality (Table 4, Fig. 4a) indicates a van't Hoff factor smaller than 1 , which is not too surprising since the molality is based on assumptions concerning average molar weight and density for fulvic acid. A recent H-TDMA study (Brooks et al., 2004) and an electrodynamic balance study (Chan and Chan, 2003) on Suwannee River Reference fulvic acid show hygroscopic growth factors similar to those found in this work (Fig. 3a). 


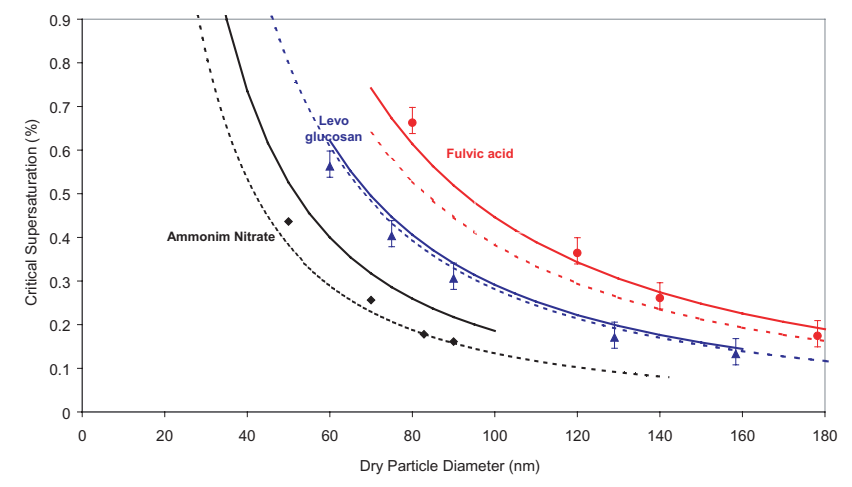

Fig. 5a. Critical supersaturation as a function of particle diameter for the pure substances. The solid lines represent the result of estimating the critical supersaturation from the parameterization of water activity as a function of molality and the surface tension. For fulvic acid, the surface tension is set to $52 \mathrm{mN} / \mathrm{m}$ for concentrations above the measurement range. The dotted red curve is obtained assuming that the surface tension decreases to $45 \mathrm{mN} / \mathrm{m}$. The dotted blue line is obtained using a van't Hoff factor of 1 together with density and molar weight for levoglucosan. The dotted black line is calculated assuming a van't Hoff factor of 2 for ammonium nitrate.

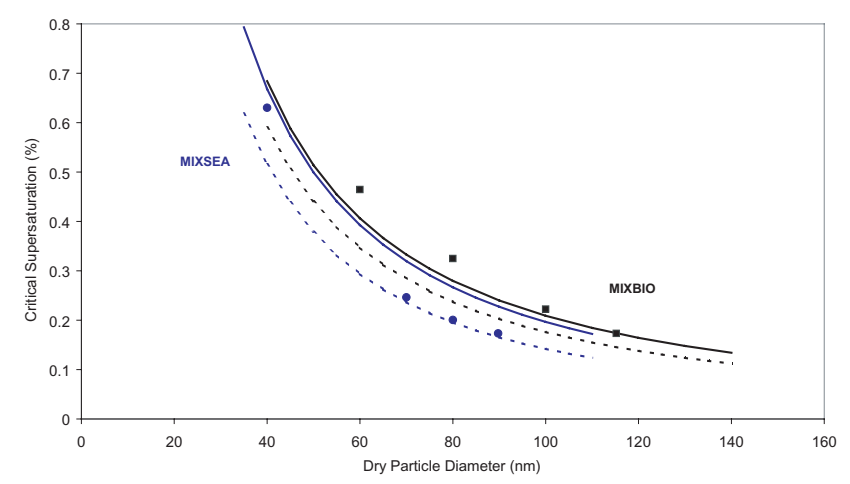

Fig. 5b. Critical supersaturation as a function of particle diameter for the mixtures MIXBIO and MIXSEA. Calculated critical supersaturations are represented by solid lines. The calculations are based on the parameterization of water activity (Table 4) and the surface tension (Table 3). The dotted blue line is obtained using a parameterization for MIXSEA, based on ZSR mixing rule (solid blue line, Fig. 3b). The dotted black line is obtained using Raoult's law and the ZSR mixing rule as described in section about MIXPO.

The modeled critical supersaturations based on H-TDMA data and surface tension agrees well with the measured (Fig. 5a). In these calculations, the parameterisation of the surface tension for fulvic acid (Table 3 ) is used in the concentration range covered by the measurements (Fig. 2a). For higher concentrations, the surface tension is kept constant at $52 \mathrm{mN} / \mathrm{m}$, corresponding to a molality in carbon of 0.42 , i.e. the highest concentration for which the surface tension was measured. Activating fulvic acid solution droplets with dry particle diameters in the range studied ( 80 to $180 \mathrm{~nm}$ )

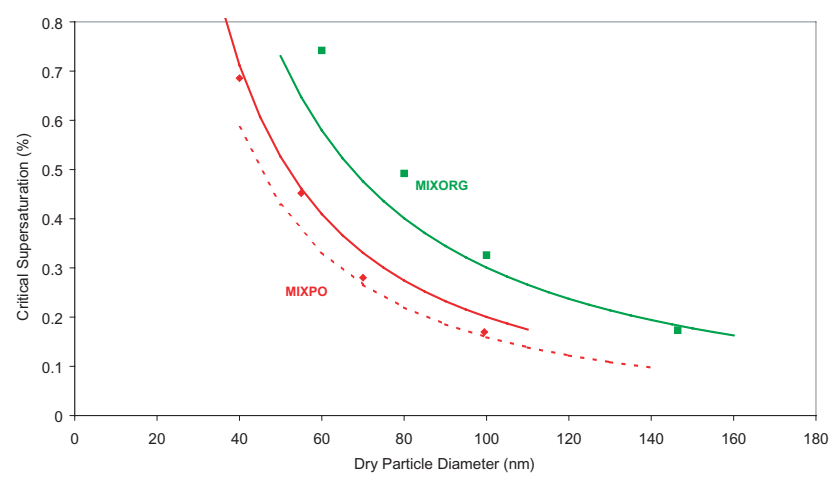

Fig. 5c. Same as Fig. 5b but for MIXPO and MIXORG. The solid lines represent the results of calculations based on the parameterizations (Table 4) and the measured surface tensions. The dotted red line is obtained using Raoult's law and the ZSR mixing rule as described in section about MIXPO.

are more concentrated than that. We thus made a sensitivity test to see the importance of the choice of the concentration cut point, above which the surface tension is assumed to be constant. If the surface tension is allowed to decrease to $45 \mathrm{mN} / \mathrm{m}$, the supersaturation is underestimated for particles with dry diameter lower than $120 \mathrm{~nm}$ (dotted line in Fig. 5a).

\subsubsection{Summarizing the pure compounds}

Both the H-TDMA data for subsaturation, and the critical supersaturations determined using the $\mathrm{CCN}$ spectrometer indicates van't Hoff factors of 1 or less for the individual organic compounds studied (succinic acid, levoglucosan, and fulvic acid). This is not to surprising, since levoglucosan (a sugar) is not expected to dissociate and succinic acid will only do so to a very low extent at the concentrations relevant for activation. A van't Hoff factor much higher than 1, would very much overestimate their water uptake at subsaturation and during activation.

Applying the parameterizations of water activity as a function of molality from the H-TDMA data and the Kelvin effect based on the measured surface tensions, gives critical supersaturations that are slightly higher than the experimental ones. In many cases, however, they are within the experimental error bars (Fig. 5a). The slight overestimation of the critical supersaturation could be due to an increasing dissociation for molalities lower than those analyzed using the H-TDMA. In the case of fulvic acid the same type of calculations gives values that are equal or lower compared to experiments. The results are, however, very sensitive to the extrapolation of surface tension data from the highest analyzed concentration, to the concentrations relevant during activation (Fig. 5a). 


\subsection{Mixtures}

\subsubsection{MIXSEA}

MIXSEA is a mixture of sodium chloride, ammonium sulfate, fulvic acid and succinic acid (Table 2).

In the hygroscopic growth of MIXSEA (Fig. 3b), the effect of deliquescence can be seen in the water activity range $0.61-0.64$. This deliquescence water activity is significantly lower than that for pure ammonium sulfate and sodium chloride. For this mixture, also the efflorescence branch of the growth curve was analyzed and the particles were not dried out completely at $40 \% R H$. When analyzing the efflorescence branch, the aerosol relative humidity was set to $85 \%$. Our data show no difference between the efflorescence and the deliquescence branch for relative humidities above $65 \%$, indicating that most of the inorganic salt that was dissolved at $85 \% R H$ also was in solution at $65 \% R H$. A parameterization of the water activity as a function of molality (Fig. 4b) is given in Table 4 .

In the case of MIXSEA, the hygroscopic growth is much smaller than expected from the ZSR method. Cohen et al. (1987) also found a deviation from ZSR for ammonium sulfate/sodium chloride mixtures. Several possible reasons for the discrepancy can be identified. In order to explain the observed growth in terms of density or shape factor, the density should be only $68 \%$ of that determined from Eq. (8) or a shape factor of 1.2 has to be used. Also loss of aerosol particle mass due to evaporation of $\mathrm{HCl}$ and $\mathrm{NH}_{3}$ could be considered.

Modeling of the crystals formed from a mixture of ammonium, sodium, chloride, and sulfate ions (http://www.hpc1. uea.ac.uk/ e770/aim.html; Wexler and Clegg, 2002; Clegg et al., 1998) shows that these ions preferentially form ammonium chloride and sodium sulfate. Also crystal structures containing all four ions are possible. If sodium sulfate crystallize to $\mathrm{Na}_{2} \mathrm{SO}_{4} \cdot 10 \mathrm{H}_{2} \mathrm{O}$, the relatively low density of this sodium sulfate crystal and the amount of water in the crystals is more than sufficient to explain the deviation from ZSR. Sodium sulfate has several different forms of crystals, with and without crystal water and with different solubility. A low solubility for sodium sulfate offers another possible explanation.

The behavior could alternatively be explained by interactions of organic compounds with sodium chloride in solution. Based on the available data, we can not make any conclusions on the reason for the deviation from the ZSR method and mixtures of sodium chloride with organic acids and with ammonium sulfate have to be studied further.

The critical supersaturation obtained using the water activity parameterization in Table 4 and the surface tension gave good agreement with measurements for particles with a diameter of $40 \mathrm{~nm}$, but overestimated the critical supersaturation for larger particles. The result of applying the ZSR method to the parameterizations for the pure compounds is presented in Fig. 3b (blue solid line). Using a parameterization of water activity as a function of molality based on this curve gave a better agreement with the measured critical supersaturations for the larger particles (Fig. 5b). This indicates that the reason for the deviation from the ZSR method found at subsaturation is most important at high concentrations, as e.g. if it is caused by a low solubility.

\subsubsection{MIXPO}

The MIXPO mixture is composed of ammonium sulfate, ammonium nitrate, levoglucosan, fulvic acid and succinic acid (Table 2). Its hygroscopic growth at subsaturation showed a deliquescence behavior and in the span 55-70\% RH (Fig. 3c) deliquescent particles as well as non- deliquescent particles existed. Below $50 \%$ and above $80 \%$ all particles were nondeliquesced and deliquesced, respectively.

For MIXPO the ZSR gives values close to the experimental hygroscopic growth, only a small overestimate can be seen (Fig. 3c): ZSR, based on the hygroscopic growth data from this study, could reproduce the results if an effective dry diameter of $97 \mathrm{~nm}$ is assumed. A parameterization of the water activity as a function of molality is given in Table 4 .

The critical supersaturations observed using the $\mathrm{CCN}$ spectrometer agree well with those calculated from the parameterisation of water activity and the surface tension data (Fig. 5c). As a comparison, calculations based on determining the water activity from Raoult's law and the ZSR mixing rule (Eq. 11), with van't Hoff factors of 1 for the organic compounds, 2 for ammonium nitrate, and 2.3 for ammonium sulfate (Low, 1969; Young and Warren, 1992) are presented in Fig. 5c (dashed red line). When applied to MIXPO, this gives a good agreement for the largest particles studied (Fig. 5c), but results in underestimates of the supersaturations for the smallest.

\subsubsection{MIXBIO}

The mixture MIXBIO consists of ammonium sulfate, levoglucosan, fulvic acid and succinic acid as described in Table 2 .

The hygroscopic growth of MIXBIO is presented in Fig. $3 \mathrm{~b}$ and it agrees well with that obtained applying the ZSR method to the parameterizations for the pure compounds. Including succinic acid, taking into account its solubility, results in a small overestimation in the water uptake compared to a small underestimate, if succinic acid is not taken into account. A solubility that decreases with the concentration of inorganic ions (Shulman et al., 1996) could possibly give an even better agreement.

The surface tension reduction as a function of $m o l \mathrm{C} / \mathrm{kg}$ water for MIXBIO, MIXPO, MIXSEA, and MIXORG is similar (Fig. 2b and Table 2). However, since MIXBIO and MIXORG contain less inorganic ions, their carbon molality 
at activation is higher, resulting in a larger reduction in the critical supersaturation.

Also for MIXBIO, the critical supersaturation is modeled using the parameterization of the water activity and the surface tension as functions of concentration. The agreement is good for the larger particles (Fig. 5b), but for particles with diameters of 60 and $80 \mathrm{~nm}$ the modeled critical supersaturations are lower than the experimental. As a comparison, calculations based on Raoult's law and the ZSR mixing rule, in the same way as for MIXPO, were made. When applied to MIXBIO, it results in underestimates of the supersaturations for particles of all sizes studied.

\subsubsection{MIXORG}

MIXORG is a mixture of three organic compounds (Table 2): levoglucosan, succinic acid and fulvic acid. The hygroscopic growth factors for this mixture are significantly lower than for the other three (Fig. 3c).

Describing the hygroscopic growth of MIXORG by adding water associated with each pure compound, i.e. the ZSR method, agrees with experimental observations if the water uptake by succinic acid, according to its solubility (88 g/l water, Saxena and Hildemann, 1996), is taken into account. If the contribution to the water uptake by succinic acid is not included, the hygroscopic growth is underestimated and unlimited solubility for succinic acid will overestimate it (Fig. 3c). A parameterization of the water activity as a function of molality is given in Table 4 . Note that the molality is calculated using Eqs. (6)-(8), assuming that everything is dissolved, not taking into account that a fraction of the succinic acid could be solid.

Experimentally determined critical supersaturations for MIXORG (Fig. 5c) are consequently much higher than those for the other 3 mixtures. The critical supersaturations obtained from the model using the water activity parameterisation (Table 4 and Fig. 4b) and the measured surface tension data (Fig. 2b) agrees well with those measured for particles with diameters of $100 \mathrm{~nm}$ or larger. For smaller particles the model underestimates the critical supersaturation. This is surprising, since all the succinic acid is not expected to be dissolved, even for the highest water activities studied with the H-TDMA (compare the dashed-dotted and solid curves for MIXORG in Fig. 3c). However, it should, according to the solubility for succinic acid, be dissolved at activation. This effect would cause an overestimation of the critical supersaturation.

\subsubsection{Summarizing the mixtures}

Based on water activity parameterizations for single compounds derived from HTDMA measurements, the ZSR mixing rule can explain the hygroscopic growth of 3 out of 4 mixtures. In one of these (MIXORG) the solubility of succinic acid has to be taken into account to achieve satisfac- tory agreement. Several other studies have found that ZSR can well describe experimental results for mixed particles. For example Choi and Chan (2002) found that mixtures of maleic and malic acids and of malonic and glutaric acids in 1:1 molar ratios follow ZSR. Brooks et al. (2004) studied humic acid of different origins and Suwannee River Reference fulvic acid mixed with ammonium sulfate and they also found that ZSR gave results that are consistent with measurements.

The only mixture containing sodium chloride (MIXSEA) shows a very pronounced deviation from ZSR. No conclusion on the reason for deviation can be drawn from the available data. However, the ions in this mixture can crystallize in several different ways, and it is not clear which salts that should be used in the ZSR mixing rule.

The parameterizations given are valid for the mixtures defined in Table 2. Changes in the composition of the mixture can cause significant changes in the hygroscopicity. This is especially the case for mixtures that deviate from the ZSR mixing rule (e.g. MIXSEA) or are dominated by a compound with low solubility (e.g. MIXORG). Replacing succinic acid in MIXORG by another dicarboxylic acid with similar density, molar weight, and van't Hoff factor but a higher solubility, would change the hygroscopic growth significantly: it would be close to the dotted line in Fig. 3c.

The parameterizations of water activity as a function of molality are used, together with the surface tension data, to estimate critical supersaturations. For MIXSEA and MIXPO the experimentally determined supersaturations are below or equal to the estimated (Figs. 5b and c). For MIXBIO and MIXORG the measured critical supersaturations are equal to or higher than the estimated (Figs. $5 \mathrm{~b}$ and c). In Fig. 6, critical supersaturations modeled using the water activity parameterizations (Table 4) are plotted against experimental results. For each mixture, a nice linearity is observed. In the case of MIXSEA and MIXPO the slope is close to 1, but for MIXBIO and MIXORG it is around 0.7. Raoult's law and the ZSR mixing rule as described above for MIXPO, gives supersaturations that are lower than those obtained from the parameterizations.

All the mixtures containing fulvic acid exhibit a decrease in the surface tension. Modeling of the Köhler curve, accounting for surface tension lowering as described above and using the parameterizations of water activity from Table 4 , show that the effect is most pronounced for MIXORG and MIXBIO $(52 \mathrm{mN} / \mathrm{m}<\sigma<60 \mathrm{mN} / \mathrm{m}$ during activation: the lowest values for the smallest particles). The effect is smaller for MIXPO and MIXSEA $(62 \mathrm{mN} / \mathrm{m}<\sigma<69 \mathrm{mN} / \mathrm{m}$ during activation), since they have larger fractions of inorganic ions and thus a lower concentration of the organic compound at activation. 


\section{Conclusions}

The present study derives new water activity parameterizations for single compound solutions, which can be used in describing the water uptake under sub- and super-saturated conditions for aerosol particles made of inorganic and organic water-soluble compounds. Also parameterizations for mixtures of model compounds are presented. To this aim, the chemical composition of the water-soluble fraction of different types of atmospheric aerosol was reproduced in laboratory and the generated aerosols were subsequently studied with a H-TDMA instrument and a CCN spectrometer. Three main types of aerosols were investigated: MIXBIO (biomass burning aerosol), MIXPO (polluted continental aerosol) and MIXSEA (polluted marine aerosol). The chemical compositions of these aerosol types were determined on the basis of the results of recent aerosol characterization experiments. In these cases, three compounds represented the organic fraction: levoglucosan, succinic acid and fulvic acid, in different percentages. In addition a mixture of these organic compounds only (MIXORG) was studied.

The hygroscopic growth and critical supersaturations for the organic compounds studied are consistent with van't Hoff factors close to one. This is expected from their low dissociation.

The ZSR method was applied to the mixtures considered in this study. The results show that the hygroscopic growth of most of the mixtures could be well described using the ZSR model, i.e. by adding the water uptake by the pure compounds. One exception is MIXSEA that showed a much smaller hygroscopic growth than expected from the ZSR model. Based on the available data, no conclusions can be made on the causes for this discrepancy, even though several possible reasons are identified. In the case of MIXORG, the limited solubility of succinic acid has to be taken into account to explain the hygroscopic growth.

Succinic acid has a low solubility, and thus a high deliquescence point. Therefore its water activity could not be determined in the H-TDMA measurements. However, in mixtures, succinic acid contributes significantly to the water uptake, especially during activation, showing that slightly soluble organic compounds are likely to influence the CCN ability of mixed inorganic/organic particles. It could be expected that a model based on the parameterization of water activity should lead to an overestimation of the critical supersaturations mixtures with a high fraction of compounds with low solubility. The comparison of the critical supersaturation measured by the CCN spectrometer for a mixed solution of only organic compounds (MIXORG: levoglucosan, succinic acid and fulvic acid) with the modeled one shows that the model underestimates the critical supersaturation for particles smaller than $100 \mathrm{~nm}$. The occurrence of slightly soluble compounds is of concern, because their water activity can be estimated only with some assumptions concerning e.g. sol-

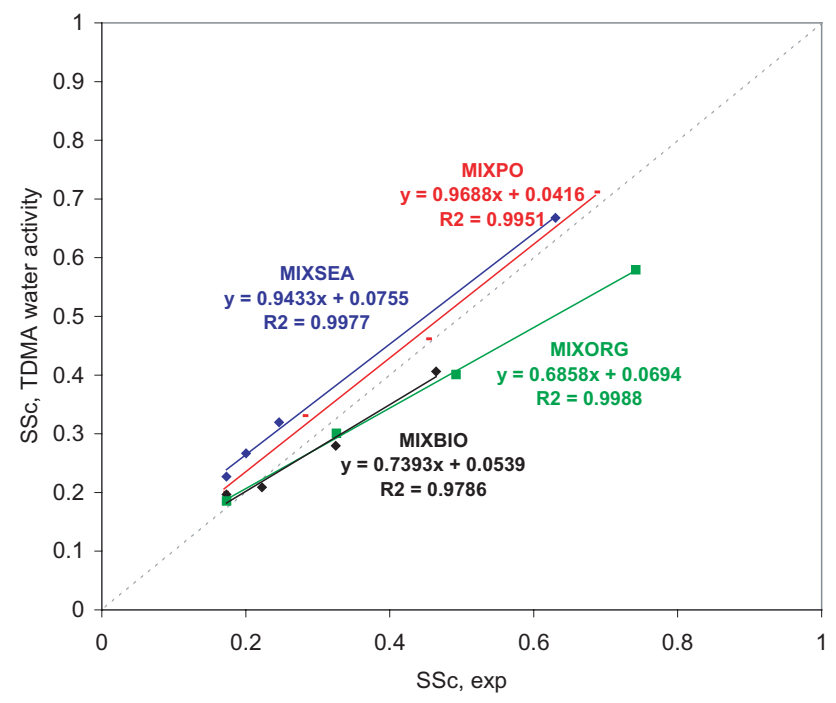

Fig. 6. The critical supersaturation calculated using the parameterizations of water activity (Table 4) and the surface tension (table 3) versus those determined experimentally for the four mixtures studied.

ubility in mixtures, introducing a source of uncertainty into modeling.

The new parameterizations of water activity are applied in the basic form of the Köhler equation (Eq. 3) to provide an estimate of the critical supersaturation as a function of particle size. The critical supersaturation of the aerosol particles of the single compound solutions and mixtures analyzed by the $\mathrm{CCN}$ spectrometer are compared with those estimated by the Köhler equation as described above. The results show that the model matches with the measurements within $0.05 \%$ of supersaturation for most of the compounds, even though it has a general tendency to overestimate it. For MIXSEA the model overestimates the critical super-saturation for all particle diameters: the theoretical critical supersaturations are 0.03 to $0.10 \%$ higher than the measured. A parameterisation based on ZSR offers a much better agreement. The good agreement for fulvic acid is only obtained if the surface tension is kept constant at molalities above the measured range. The model is adequate in forecasting the critical supersaturation for MIXBIO particles with diameters of $100 \mathrm{~nm}$ or larger, whereas it underestimates the critical supersaturation for smaller particles.

The surface tension lowering as a function of concentration of carbon atoms is similar for the four mixtures containing fulvic acid. The effect on the critical supersaturation is, however, most pronounced for MIXBIO, MIXORG, and fulvic acid, since they contain only small amounts of inorganic ions. 
Acknowledgements. This work is supported by the EU Commission under contracts EVK2-CT-2001-00110 (SMOCC), and EVK2-2001-00002 (PHEONICS), the Swedish Research Council under contract 621-2001-2480, the Danish Natural Science Research Council under grants 21020377, 21010250, and 9901450, the Italian Ministry of Environment (Italy-USA Cooperation on Science and Technology of Climate Change), and Åse og Ejnar Danielsens Fond (The Environmental Award 2003). We also want to thank the Nordic Center of Excellence, Research unit on Biosphere-Atmosphere-Cloud-Climate-Interactions (BACCI) for its support.

Edited by: A. Nenes

\section{References}

Andreae, M. O., Rosenfeld, D., Artaxo, P., Costa, A. A., Frank G. P., Longo K. M., and Silva-Dias, M. A. F.: Smoking rain clouds over the Amazon, Science, 303, 1337-1342, 2004.

Ansari, A. S. and Pandis, S. N.: Water absorption by secondary organic aerosol and its effect an inorganic aerosol behavior, Environ. Sci. Technol., 34, 71-77, 2000.

Artaxo, P., Martins, J. V., Yamasoe, M. A., Procópio, A.S., Pauliquevis, T. M., Andreae, M. O., Guyon, P., Gatti, L. V., and Leal, A. M. G.: Physical and chemical properties of aerosols in the wet and dry season in Rondonia, Amazonia, J. Geophys. Res., 107, doi:0.1029/2001JD000666, 2002.

Averett, R. C., Leenheer, J. A., McKnignt, D. M. , and Thorn, K. A.: Humic substances in the Suwannee River, Georgia: Interactions, properties, and proposed structures, U.S.G.S. report, 1989.

Bilde, M. and Svenningsson, B.: CCN activation of slightly soluble organics: importance of small amounts of inorganic salt and particle phase, Tellus B, 56, 128-134, 2004.

Brechtel, F. J. and Kreidenweis, S. M.: Predicting particles critical supersaturation from hygrscopic growth measurements in the humidified TDMA. Part II: Laboratory and Ambient Studies, J. Atmos. Science, 57, 1872-1887, 2000.

Broday, D. M. and Georgopoulos, P. G.: Growth and deposition of hygroscopic particulate matter in the human lungs, Aerosol Sci. Technol., 34, 144-159, 2001.

Broekhuizen, K., Kumar, P. P., and Abbatt, J. P. D.: Partially soluble organics as cloud condensation nuclei: Role of trace soluble and surface active species, Geophys. Res. Lett., 31, doi:10.1029/2003GL018203, 2004.

Brooks, S. D., DeMott, P. J., and Kreidenweis, S. M.: Water uptake by particles containing humic materials and mixtures of humic materials with ammonium sulfate, Atmos. Environ., 38, 18591868, 2004.

Chan., H.-K., Eberl, S., Daviskas, E., Constable, C., and Young, I.: Changes in lung deposition of aerosols due to hygroscopic growth: a Fast SPECT study, J. Aerosol. Med., 15, 307-311, 2002.

Chan, M. N. and Chan, C. K.: Hygroscopic properties of two model humic-like substances and their mixtures with inorganics of atmospheric importance, Environ. Sci. Technol., 37, 5109-5115, 2003.

Chan, M. N., Choi, M. Y., Ng, N. L., and Chan, C. K.: Hygroscopicity of water-soluble organic compounds in atmospheric aerosols:
Amino acid and biomass burning derived organic species, Environ. Sci. Technol., 39, 1555-1562, 2005.

Charlson, R. J., Seinfeld, J. H., Nenes, A., Kulmala, M., Laaksonen, A., and Facchini, M. C.: Reshaping the theory of cloud formation, Science, 292, 2025-2026, 2001.

Chebbi, A. and Carlier, P.: Carboxylic acids in the troposphere, occurence, sources, and sinks: A riview, Atmos. Eviron., 30, 42334249, 1996.

Choi, M. Y. and Chan, C. K.: Continuous measurements of the water activities of aqueous droplets of water-soluble organic compounds, J. Phys. Chem. A , 106, 4566-4572, 2002.

Clegg, S. L., Brimblecombe, P., and Wexler, A. S.: A thermodynamic model of the system $\mathrm{H}^{+}-\mathrm{NH}_{4}^{+}-\mathrm{Na}^{+}-\mathrm{SO}_{4}^{2-}-\mathrm{NO}_{3}^{-}-\mathrm{Cl}^{-}$$\mathrm{H}_{2} \mathrm{O}$ at 298.15 K, J. Phys. Chem. A, 102, 2155-2171, 1998.

Cohen, M. D., Flagan, R. C., and Seinfeld, J. H.: Studies of concentrated electrolyte solutions using the electrodynamic balance. 2 . Water activities for mixed-electrolyte solutions, J. Phys. Chem., 91, 4575-4582, 1987.

Corrigan, C. E. and Novakov, T.: Cloud condensation nucleus activity of organic compounds: a laboratory study, Atm. Environ., 33, 2661-2668, 1999.

Cruz, C. N. and Pandis, S. N.: A study of the ability of pure secondary organic aerosol to act as cloud condensation nuclei, Atm. Environ., 31, 2205-2214, 1997.

Decesari, S., Facchini, M. C., Fuzzi, S., and Tagliavini, E.: Characterization of water-soluble organic compounds in the atmospheric aerosol: A new approach, J. Goephys. Res., 105, 14811489, 2000.

Decesari, S., Facchini, M. C., Matta, E., Lettini, F., Mircea, M., Fuzzi, S., Tagliavini, E., and Putaud, J.-P.: Chemical features and seasonal variation of fine aerosol water-soluble organic compounds in the Po Valley, Italy., Atm. Environ., 35, 3691-3699, 2001.

Decesari, S., Facchini, M. C., Mircea, M., Cavalli, F., and Fuzzi, S.: Solubility properties of surfactants in atmospheric aerosol and cloud/fog water samples, J. Geophys. Res., 108, 4685, doi:10.1029/2003JD003566, 2003.

Facchini, M. C., Mircea, M., Fuzzi, S., and Charlson, R. J.: Cloud albedo enhancement by surface-active organic solutes in growing droplets, Nature, 401, 257-259, 1999.

Facchini, M. C., Mircea, M., Fuzzi, S., and Charlson, R. J.: Comments on "Influence of Soluble Surfactant Properties on the Activation of Aerosol Particles Containing Inorganic Solute", J. Atmos. Sci., 58, 1465-1467, 2001.

Ferron, G. A., Kreyling, W. G., and Haider, B.: Inhalation of salt aerosol particles-II. Growth and deposition in the human respiratory tract, J. Aerosol Sci., 19, 611-631, 1988.

Fuzzi, S., Descesari, S., Facchini, M. C., Matta , E., Mircea, M., and Tagliavini: A simplified model of the water soluble organaic component of atmospheric aerosols, Geophys. Res. Lett., 20, 4079-4082, 2001.

Gysel M., Weingartner E., and Baltensperger U.: Hygroscopicity of aerosol particles at low temperatures. 2. Theoretical and experimental hygroscopic properties of laboratory generated aerosols, Environ. Sci. Technol., 36, 63-68, 2002.

Henning, S., Rosenørn, T., D’Anna, B., Gola , A. A., Svenningsson, B., and Bilde, M.: Cloud droplet activation and surface tension of mixtures of slightly soluble organics and inorganic salt, Atmos. Chem. Phys., 5, 575-582, 2005. 
Hinds, W. C.: Aerosol technology, John Wiley \& Sons, Inc., New York, 1999.

Hori, M., Ohta, S., Murao, N., and Yamagata, S.: Activation capability of water soluble organic substances as CCN, J. Aerosol Sci., 34, 419-448, 2004.

Hänel, G.: The properties of atmospheric aerosol particles as functions of the relative humidity at thermodynamic equilibrium with the surrounding mois air, Adv. Geophys., 19, 74-183, 1976.

Intergovernmental Panel on Climate Change (IPCC): Climate change: the scientific bases, Cambridge University Press, UK, 2001.

Kanakidou, M., Seinfeld, J. H., Pandis, S. N., Barnes, I., Dentener, F. J., Facchini, M. C., van Dingenen, R., Ervens, B., Nenes, A. N. C. J. S. E., Putaud, J. P., Balkanski, Y., Fuzzi, S., Horth, J., Moortgat, G. K., Winterhalter, R., Myhre, C. E. L., Tsigaridis, K., Vignati, E., Stephanou, E. G., and Wilson, J.: Organic aerosol and global climate modelling: a review, Atmos. Chem. Phys., 5, 1053-1123, 2005.

Kaufman, Y. J., Tanré D., and Boucher, O.: A satellite view of aerosols in the climate system, Nature, 419, 215-223, 2002.

Kawamura, K., Yokoyama, K., Fujii, Y., and Watanabe, O.: A Greenland ice core record of low molecular weight dicarboxylic acids, ketocarboxylic acids, and $\alpha$-dicarbonyls: A trend from Little Ice Age to the present (1540 to 1989 A.D.), J. Geophys. Res., 106, 1331-1345, 2001a.

Kawamura, K., Steinberg, S., Ng, L., and Kaplan, I. R.: Wet deposition of low molecular weight mono- and di-carboxylic acids, aldehydes, and inorganic species in Los Angeles, Atmos. Environ., 35, 3917-3926, 2001b.

Kerminen, V.-M., Ojanen, C., Pakkanen, T., Hillamo, R., Aurela, M., and Merilainen, J.: Low-molecular-weight dicarboxylic acids in an urban and rural atmosphere, J. Aerosol Sci., 31, 349$362,2000$.

Kreidenweis, S. M., Koehler, K., DeMott, P. J., Prenni, A. J., Carrico, C., and Ervens, B.: Water activity and activation diameters from hygroscopicity data - Part I: Theory and application to inorganic salts, Atmos. Chem. Phys, 5, 1357-1370, 2005.

Langmuir, I.: The constitution and fundamental properties of solid and liquids. II. Liquids., J. Amer. Chem. Soc., 39, 1848-1906, 1917.

Li, Z., Williams, A. L., and Rood, M. J.: Influence of soluble surfactant properties on the activation of aerosol particles containing inorganic solute, J. Atmos. Sci., 55, 1859-1866, 1998.

Loglio, G., Pandolfini, P., Tesei, U., and Noskov, B.: Measurements of interfacial properties with the axisymmetric bubbleshape analysis technique: effects of vibrations, Coll. Surf. A, 143, 301-310, 1998.

Low, D. H.: A theoretical study of nineteen condensation nuclei, J. de Recherches Atmospheric, 4, 65-78, 1969.

Mayol-Bracero, O. L., Guyon, P., Graham, B., Roberts, G. C., Andreae, M. O., Decesari, S., Facchini, M. C., Fuzzi, S., and Artaxo, P.: Water-soluble organic compounds in biomass burning aerosols over Amazonia: 2. Apportionment of the chemical composition and importance of the polyacidic fraction., J. Geophys. Res., 107, 8091, doi:10.1029/2001JD000522, 2002.

Mikhailov, E., Vlasenko, S., Niessner, R., and Pöschl, U.: Interaction of aerosol particles composed of protein and salts with water vapor: hygroscopic growth and microstructural rearrangement, Atmos. Chem. Phys., 4, 323-350, 2003.
Mochida, M. and Kawamura, K.: Hygroscopic properties of levoglucosan and related organic compounds characteristic to biomass burning aerosol particles, J. Geophys.Res., 109, D21202, doi:10.1029/2004JD004962, 2004.

Narukawa, M., Kawamura, K., Li, S. M., and Bottenheim, J. W.: Dicarboxylic acids in the Arctic aerosols and snowpacks collected during ALERT 2000, Atmos. Envir., 36, 2491-2499, 2002.

Nenes, A., Charlson, R. J., Facchini, M. C., Kulmala, M., Laaksonen, A., and Seinfeld, J. H.: Can chemical effects on cloud droplet number rival the first indirect effect?, Goephys. Res. Lett., 29, 1848-1851, 2002.

Peng, C., Chan, M. N., and Chan, C. K.: The hygroscopic properties of dicarboxylic and multifunctional acids: measurements and UNIFAC predictions, Envir. Sci. Technol., 35, 4495-4501, 2001.

Penner, J. E., Dong, X., and Chen, Y.: Observational evidence of a change in the radiative forcing due to the indirect aerosol effect, Nature, 427, 231-234, 2004.

Prenni, A. J., DeMott, P. J., Kreindenwies, S. M., Sherman, D. E., Russel, L. M., and Ming, Y.: The effects of low molecular weight dicarboxylic acids on cloud formation, J. Phys. Chem. A, 105, 11 240-11 248, 2001.

Pöschl, U., Krämer, L., and Niessner, R.: Microstructural rearrangement of sodium chloride condensation aerosol particles on interaction with water vapour, J. Aerosol Sci., 31, 673-685, 2000.

Raes, F., van Dingenen, R., Vignati, E., Wilson, J., Putaud, J. P., Seinfeld, J. H., and Adams, P.: Formation and cycling of aerosols in the global troposphere, Atmos. Environ., 34, 4215-4240, 2000.

Ramanathan, V., Crutzen, P. J., Kiehl, J. T., and Rosenfeld, D.: Aerosols, climate, and the hydrological cycle, Science, 294, 2119-2124, 2001.

Raymond, T. R. and Pandis, S. N.: Cloud activation of singlecompound organic aerosol particles., J. Geophysic. Res., 107, 4787, doi:10.1029/2002JD002159, 2002.

Raymond, T. R. and Pandis, S. N.: Formation of cloud droplets by multi-component organic aerosol particles, J. Geophys. Res., 108, 4469, doi:10.1029/2003JD003503, 2003.

Rood, M. J. and Williams, A. L.: Reply to Comments on "Influence of soluble surfactant properties on the activation of aerosol particles containing inorganic solute”, J. Atmos. Sci., 58, 1468-1473, 2001.

Saxena, P. and Hildemann, L. M.: Water-soluble organics in atmospheric particles: A critical review of the literature and application of thermodynamics to identify candidate compounds, J. Atmos. Chem., 24, 57-109, 1996.

Schroeter, J. D., Musante, C. J., Hwang, D., Burton, R., Guilmette, R., and Martonen, T. B.: Hygroscopic growth and deposition of inhaled secondary cigarette smoke in human nasal pathways, Aerosol Sci. Technol., 34, 137-143, 2001.

Shimmo, M., Anttila, P., Hartonen, K., Hyötyläinen, T., Paatero, J., Kulmala, M., and Riekkola, M.-L.: Identification of organic compounds in atmsopheric aerosol particles by online supercritical fluid extraction-liquid chromatography-gas chromatography-mass spectrometer, J. Chromat., 151-159, 2004.

Shulman, M. L., Jacobson, M. C., Charlson, R. J., Synovec, R. E., and Young, T. E.: Dissolution behavior and surface tension effects of organic compounds in nucleating cloud droplets, Geophys. Res. Lett., 23, 277-280, 1996. 
Simoneit, B. R. T., Schauer, J. J., Nolte, C. G., Oros, D. R., Elias, V. O., Fraser, M. P., Rogge, W. F., and Cass, G. R.: Levoglucosan, a tracer for cellulose in biomass burning and atmospheric particles, Atm. Environ., 33, 173-182, 1999.

Sorjamaa, R., Svenningsson, B., Raatikainen, T., Henning, S., Bilde, M., and Laaksonen, A.: The role of surfactants in Köhler theory reconsidered, Atm. Chem. Phys., 4, 2107-2117, 2004.

Stokes, R. H. and Robinson, R. A.: Interactions in aqueous nonelectrolyte solutions: I. Solute-solvent equilibria., J. Phys. Chem., 70, 2126-2130, 1966.

Stolzenburg, M. R. and McMurry, P. H.: Particle Technology Laboratory, Department of Mechanical Eng., University of Minnesota, Minneapolis, MN, USA, 1988.

Svenningsson, B., Hanson, H.-C., Swietlicki, E., Berg, O., and Zhou, J.: Design and laboratory tests of a tandem differential mobility analyzer for hygroscopic growth measurements, Lund University, Lund, Sweden, 1997.

Svenningsson, B., Hansson, H.-C., Wiedensohler, A., Noone, K., Ogren, J., Hallberg, A., and Colvile, R.: Hygroscopic growth of aerosol particles and its influence on nucleation scavenging in cloud: experimental results from Kleiner Feldberg, J. Atmos. Chem., 19, 129-152, 1994.

Tang, I. N.: Chemical and size effects of hygroscopic aerosols on light scattering coefficients, J. Geophys. Res., 101, 19245$19250,1996$.
Tang, I. N. and Munkelwitz, H. R.: Water activities, densities and refractive indices of aqueous sulfates and sodium nitrate droplets of atmospheric importance, solutions , J. Geophys. Res., 99, 18 801-18 808, 1994.

Twomey, S.: The influence of pollution on the shortwave albedo of clouds, J. Atmos. Sci., 34, 1149-1152, 1977.

Wexler, A. S. and Clegg, S. L.: Atmospheric aerosol models including $\mathrm{H}^{+}, \mathrm{NH}_{4}^{+}, \mathrm{Na}^{+}, \mathrm{SO}_{4}^{2-}, \mathrm{NO}_{3}^{-}, \mathrm{Cl}^{-}, \mathrm{Br}^{-}$and $\mathrm{H}_{2} \mathrm{O}, \mathrm{J}$. Geophys. Res., 107, 4207, doi:10.1029/2001JD000451, 2002.

Young, K. C. and Warren, A. J.: A reexamination of the derivation of the equilibrium supersaturation curve for soluble particles, J. Atmos. Sci., 49, 1138-1143, 1992.

Zappoli, S., Andracchio, A., Fuzzi, S., Facchini, M. C., Gelencser, A., Kiss, G., Krivacsy, Z., Molnar, A., Meszaros, E., and Hansson, H. C.: Inorganic, organic and macromolecular components of fine aerosol in different areas of Europe in relation to their water solubility, Atm. Envir., 33, 2733-2743, 1999.

Zhou, J.: Hygroscopic properties of atmospheric aerosol particles in various environments, PhD thesis, Lund University, Lund, Sweden, 2001.

Zill, D. G. and Cullen, M. R.: Advanced engineering mathematics, 2nd edition, Jones and Bartlett Publishers, Boston, 2000. 